\title{
The Relationship between Employee Advocacy and Psychological Well-Being: Mediating Role of Perceived Insider Status and Moderating Role of Power Distance
}

\author{
Daimi KOÇAK ${ }^{1}$
}

https://orcid.org/0000-0001-9099-2055

\begin{abstract}
The purpose of this study is to examine the relationships between employee advocacy and psychological well-being (PWB), and to test the mediating effect of perceived insider status (PIS), and moderating effect of power distance on that relationship within the framework of social exchange theory. Data were collected using a questionnaire survey method from 293 full-time employees working in an organization operating in the aviation industry in Turkey. The data obtained were analyzed according to the moderated mediation (alternatively known as condational indirect effect) framework improved by Preacher et al. (2007). Research findings are demonstrated that the relationship between employee advocacy and PWB is more complex than was prior researchers' findings. As a result of analyzes, it was determined that PIS has a partial mediation effect on the relationship between employee advocacy and PWB. Also the results supported the moderated mediation and showed that the positive indirect effect of employee advocacy on PWB through PIS was stronger for employees with low power distance perception. The theoretical and practical implications of findings are discussed.
\end{abstract}

Keywords: Employee advocacy, perceived insider status, power distance, psychological well-being, aviation industry.

Jel Codes: D23, M12, M14, 131

\section{INTRODUCTION}

Since service industry employees are in direct and close contact with customers, their attitudes and behaviors affect customer perception and satisfaction (Chan and Wan, 2012). For this reason, companies operating in the service sector must employ appropriate people to manage and motivate them successfully (Yeh, 2014). The concept of PWB was described as positive emotions more dominant than negative ones by Bradburn (1969). In later years, Bradburn's work was criticized for focusing too much on positive and negative emotions. PWB was conceptualized as a combination of positive affective state included both the degree of individuals' positive emotions and meaningfulness of their lives, and generally expressed as happiness (hedonic perspective) and full self-actualization of an individual (eudaimonic perspective) (Winfield et al., 2012). In this research, well-being is handled according to the approach of the eudaimonic perspective developed by Ryff (1989).

Thanks to employees with a high level of PWB, organizations achieve their goals more easily. Similarly, as the working life is an important part of most people, it has a great impact on their well-being (Zheng et al., 2015). To help employees feelings themselves psychologically better, organizations must be support employees socially and economically (Kim, 2008). With that in mind, evaluation according to social exchange (Blau, 1964) and incentive-contribution theories (March and Simon, 1958), it can be interpreted as that an employee will be more motivated for the contribution to the organizational outputs in return for some benefits (promotion, participative management, etc.) provided by the organization. For example, studies (Wright and Cropanzano, 2000, 2004; Daniels and Harris, 2000),

\footnotetext{
${ }^{1}$ Assistant Professor, Erzincan Binali Yıldırım University, Ali Cavit Çelebioğlu Civil Aviation School, Erzincan, Turkey, dkocak@erzincan.edu.tr
} 
investigating the relationship between PWB and employee performances found that increasing the well-being of the employees affects their performance. PWB will enhance employees' performances which will pave the way to the achievement of organizational goals (Wright and Cropanzano, 2004).

The aviation sector is one of the sensitive sectors that are affected by many factors (e.g. government policy decisions, economic crises, customer expectations). Customers are in close contact with ground handling employees from the moment they arrive at the airport until they leave the airport. Therefore, the quality of the service they provide has a significant impact on customer satisfaction (Yeh, 2014). Ground handling employees must be able to immediately resolve customers' problems in order to develop and maintain the company's overall image of providing high-quality service (Türeli et al., 2019). The attitudes and behaviors of ground handling workers significantly affect the perception of service of customers (Ban and Kim, 2019). Therefore, ground handling companies must develop methods to effectively manage their employees and ensure that their attitudes and behaviors are conducive to providing quality service. The aviation industry is an industry where employees'PWBs are significant (Rosskam et al., 2009). Meeting the increasing customer expectations depends on the psychological well-being of the ground handling employees. For this reason, it was considered that it would be appropriate to implement the study on service industry employees whose PWBs could have a direct effect on the activities carried out and customer satisfaction. In addition, the power distance variable included in the model as a moderator variable is an important determinant in the aviation industry, where teamwork and communication are extremely important (Helmreich ve Merritt, 2001). Employee advocacy is related to the transparency of an airline company's employment offers, and their willingness to act in the best interests of their employees. Yeh (2014) found that employee advocacy is an important determinant of job satisfaction and loyalty of employees in the aviation industry. Therefore, in this study, the effect of the employee advocacy, perceived insider status, and power distance on the psychological well-being of the ground service employees was investigated.

This article contributes to the literature in two ways. First, as a result of the literature research, no study was found to investigate the relationship between employee advocacy and PWB. The present study is significant as it examined the influences of informal organizational support (employee advocacy in this work) and employees' organizational identification (PIS in this work) on their PWBs in the context of organizational culture (power distance in this work). In this research, the direct effect of employee advocacy on employees' PWBs and its indirect effect through PIS were investigated. Also, the moderating effect of power distance, one of Hofstede's (1980) cultural dimensions, on this interaction was examined. Second, the findings of this study contribute to future studies' better understanding of outcomes of employee advocacy. Having reviewed the concerning literature, I realized that very few studies have investigated the outcomes of employee advocacy (e.g., Yeh, 2014; Akgunduz and Sanli, 2017). This study aims to explain the importance of employee advocacy and PIS on PWB according to the level of power distance. For this purpose in this study, firstly, employee advocacy, PIS, power distance, and PWB concepts were handled in the theoretical framework. Then, the interactions of these scales with each other were statistically analyzed, and the theoretical and practical effects of the obtained data were discussed, and suggestions were made to managers and future studies.

\section{THEORETICAL FRAMEWORK AND HYPOTHESES}

\subsection{Employee Advocacy}

The relationship between employees and employers is always pointed out as a mutual exchange relationship (Homans, 1961). This relationship usually includes economic (material objects such as money) and social elements (intangible objects such as mutual trust and courtesy). While the expectations for economic exchange relationships are clearly defined by informal agreements (Cropanzano and Mitchell, 2005), the reciprocal expectations of the two parties are not clearly stated in social exchange (Emerson, 1976). For this reason, it is of utmost importance that both parties trust each other in the social exchange relationship. Social exchange is a process in which two or more people are mutually dependent to each other (Blau, 1964). The foundation of social exchange theory is based on the reciprocal trust and expectation of the parties in labor relations (Cropanzano and Mitchell, 2005). One of these expectations for an employee is "employee advocacy" (Yeh, 2014). Employee advocacy is defined as an organization considering complaints of the employees, protecting employees from discriminatory work practices and sexual harassment, being fair in rewarding, (Kim, 2009) transparency of 
organizational policy and tendency to best fulfill the interests of employees (Akgunduz and Sanlı, 2017). Organizations ensure that employees have confidence in their work thanks to the practices contrary to the standard competitive conditions while appropriate for the employees' interests. Employee advocacy refers the transparency of an organization's employement policy, and concerns the willingness of the organization to act for the benefit of its employees (Yeh, 2014).

Employee advocacy is an important determinant that shapes the attitudes and behaviors of employees, especially in organizations in the service sector where human relations are at the forefront. There is not a lot of work in the literature about employee advocacy, which has been attracted by researchers in recent years (e.g. Yeh, 2014; Akgunduz and Sanlı, 2016; Dalgıc et al., 2016). Prior research indicated that employee advocacy has positive effect on job satisfaction and organizational commitment (Yet, 2014), and negative effect on role conflict (Dalgıc et al., 2016) and turnover intention (Aykan and Akgul, 2018).

\subsection{Employee Advocacy and Psychological Well-Being}

Employee advocacy concerns an employee's perception of the extent to which an organization values their contributions, and cares about their well-being (Yeh, 2014). The concept of PWB, first described by Bradburn (1969), was explained according to positive and negative psychological states. If a person's positive feelings are more than his/her negative feelings, he/ she will perceive life better and vice versa (Diener, 2010). PWB was expressed as "a person's sense of self-acceptance, having positive relations with other individuals he/she interacts with, being independent in determining his/her future, being aware of his/her strengths and weaknesses, finding his/her life meaningful and giving importance to his/her personal growth" (Ryff, 1989; Ryff and Keyes, 1995). While early studies conducted on well-being reflect the hedonic approach (subjective well-being) focusing on feeling good, happy, being satisfied with life; the studies carried out after the 2000s deal with a eudaimonic approach concentrating on people's psychological functioning and self-actualization (Ryff, 1989). Social exchange theory emphasizes that mutual trust is of utmost importance, employees who perceive their contribution to the organization is appreciated, develop positive feelings towards their work and organizations (Akgunduz and Sanlı, 2017). One way to support and improve employees' well-being is to implement transparent policies that strengthen the employment relationship (Yeh, 2014). Without employee advocay, employees may be undesirable, worried about the future of their employment, and may suspect management practices or decisions taken by those in authority. The PWB of the employees in organizations, where organizational policies are determined transparently and happiness of employees have cared, is at a high level (Ni and Wang, 2015; Caesens et al., 2016). Based on these informations, the following hypothesis has been developed:

Hypothesis 1(H1): Employee advocacy will affect psychological well-being positively.

\subsection{Employee Advocacy and PIS}

One of the important perceptions as a result of the employee-employer relationship is PIS. PIS is defined as the extent to which an employee perceives him or herself as an insider within a particular organization. Employees with a high level of PIS perceive themselves as a part of their organization and obtain diverse awards and incentives compared to those with a low level of PIS (Stamper and Masterson, 2002). According to social exchange theory, organizations reward employees with greater contribution to the organization than those with lower levels (Blau, 1964). Similarly, according to the incentive-contribution theory (March and Simon, 1958), employees receiving more incentives are obliged to contribute more. As this incentive-contribution cycle continues, differences arise in the evaluation of employees. This situation causes some employees to perceive themselves as more valuable for the organization than others (Raub, 2016). Factors such as supervisor support, delegation, participation in decisions and leader-member exchange relationship affect employees'PIS positively (Dai and Chen, 2015). Stamper and Masterson (2002) indicated that the benefits of the organization to the employees play an important role in the formation of the PIS. Therefore, one may infer that employee advocacy would significantly relate to PIS. If an employee gains some benefits (e.g., promotion, career development, information sharing, and training opportunity) as a result of his/her contributions to the organization, his/her PIS will increase (Stamper and Masterson, 2002). As a consequence, it is expected that employe advocacy perceptions of grond handling employees affect their PIS positively. Thus, when these explanations are taken into account, Hypothesis 2 has been put forward:

Hypothesis 2(H2): Employee advocacy will affect perceived insider status positively. 


\subsection{PIS and PWB}

Researchers have been discussing the growing relationship between employees and organizations for many years. This relationship can be conceptualized by the changes taking place between employees and organizations. According to social exchange theory, PIS is related to the mutual transfer of intangible expectations of employees from their managers or organizations (Horng et al., 2016). PIS levels may vary depending on the quality of the exchange relationship between organizations and employees. For instance, if organization provides training for employee and offers opportunities for his/her promotion, employee contributes to organizational outputs more (Buonocore et al., 2009; Stamper and Masterson, 2002). Similarly, leader-member exchange (LMX) theory argues that there is a two-way relationship between a leader and his/her follower(s) and that the leader allocates more resources (money, information, etc.) to employees (in-group) providing high contribution to the organization than those (out-group) with low contribution (Graen and Uhl-Bien, 1995).) If employees feel that they have a satisfactory exchange relationship with their organizations, their well-being will increase (Eisenberger et al., 2001). Moreover, Volmer et al., (2011) revealed that employees having high-quality relationships with their leaders (internal group) have a higher level of well-being than employees having low-quality relationships with their leaders (external group). Based on the reciprocity principle of the social exchange theory, when the employees perceive high level insider status, they feel better psychologically (Dai and Chen, 2015). Therefore, it can be asserted that there may be a positive relationship between PIS and PWB. From this analysis, I propose the following hypothesis:

Hypothesis 3(H3): Perceived insider status will affect psychological well-being positively.

\subsection{The Mediating Role of PIS}

Insider-outsider (Lindbeck and Snower, 2001), incentive-contribution (March and Simon, 1958) and LMX (Graen and Uhl-Bien, 1995) theories argue that workers making an extra contribution to the organization (insider) have more privileges (incentive, promotion, etc.) than those making a low contribution (outsider). The main focus of these theories is the more valuable employee's contribution to the organization, the more likely to benefit from organizational resources. According to March and Simon (1958), organizations reward employees as much as their contribution to outputs. These awards may be tangible (e.g. money) or intangible (e.g. trust). Employee advocacy is expressed as an intangible award, which increases the employee's PIS and PWB. According to Ryff and Keyes (1995), PWB has a multidimensional structure (e.g., autonomy, self-acceptance). Therefore there may be many factors that affect well-being at the same time. In this direction, I supposed that employee advocacy can positively contribute to psychological well-being by increasing perceived insider status.

Hypothesis 1 predicts a positive relationship between employee advocay and PWB, Hypothesis 2 predicts positive relationship between employee advocacy and PIS, and Hypothesis 3 predicts a positive relationship between PIS and PWB. Together, these hypotheses specify a model in which employee advocacy indirectly enhance PWB by contributing to PIS. In this study, I suggest that PIS mediate the employee advocacy-PWB relationship. In light of theoretical explanations, Hypothesis 4 was formed as follows:

Hypothesis 4(H4): PIS will mediate the relationship between employee advocacy and PWB.

\subsection{The Moderating Role of Power Distance}

The issue that increasing employees' PIS would have a positive impact on their PWBs was examined in terms of some theories (e.g. social exchange theory, LMX theory). However, there are several individuals (personality traits, experience, age, gender, etc.) and organizational (organizational structure, culture, activity area, etc.) factors that may affect this interaction (positive or negative). The concept of power distance was first defined by Hofstede (1980) as a dimension of organizational culture in consequence of the survey applied to a total of 116,000 IBM employees in more than 50 countries. Hofstede (1984) believed, "power distance is the fact that less powerful members of groups, organizations, and countries accept that power is distributed unequally". In organizations with high power distance, employees obey their supervisors, trying not to interfere, and accept their orders without questioning them. In these organizations; the difference between superior and subordinate is significantly high (Yayla-Kullu et al., 2015); participation of subordinates on the decision-making process is low; the difference among wages is high; the control mechanism is solid, and there is a centralized organizational structure (Bergiel et al., 2012). But in organizations with low power distances, employees have the right to constructively criticize their superiors. In organizations with such 
culture, employees often take part in decision-making process; they believe that compensation is fair; all employees are rewarded fairly; control mechanism is not solid and there is a decentralized organizational structure (Hofstede, 1984). It is important to understand power distance in organizations because all relations in organizations are power-based, and power distance affects many organizational processes and outputs directly or indirectly (Daniels and Greguras, 2014). In this study, the moderating effect of power distance to this interaction was investigated. Power distance was used as a moderating variable in many studies (e.g., Zhang and Begley, 2010; Rafei, 2013; Purwanto, 2018; Thomas, 2015; Gul et al., 2018). In general, these studies showed that in organizations with high power distance, employees' loyalty to the organization (Rafei, 2013), their job satisfaction (Purwanto, 2018; Rafei, 2013), and empowerment (Zhang and Begley, 2010) were less than in organizations with low power distance. Employees' attitudes and behaviors vary from culture to culture according to cultural values (Gul et al., 2018). In low-power organizations, employees are more likely to participate in decisions than in high-power organizations (Zhang and Begley, 2010), and have higher autonomy (Thomas, 2015) than in organizations with high power distances. Steel et al. (2018) found that in societies with low power distances, the subjective well-being of individuals is higher than that of individuals with high power distances. In organizations with high power distance organizational policies are not transparency (Giapponi and Scheraga, 2007), and the PIS of employees is low (Zheng et al., 2019). In line with these explanations, hypotheses 5 and 6 were developed:

Hypothesis 5(H5): Power distance will moderate the relationship between PIS and psychological well-being, such that the positive relationship between perceived insider status and psychological well-being will be stronger when power distance is low rather than high.

Hypothesis 6(H6): Power distance will moderate the positive and indirect effect of employee advocacy on psychological well-being through PIS, such that this indirect effect will be stronger when power distance is low rather than high.

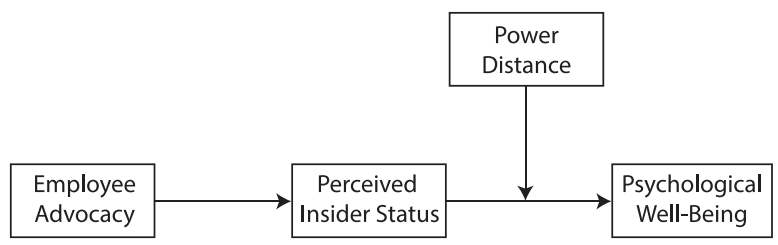

Figure 1: Hypothesized Model

\section{METHOD}

\subsection{Participants}

In this study, data were collected from the 293 out of 500 full-time employees of a ground handling company operating in the aviation industry in Turkey. The scales used in the research were previously adapted to Turkish by the researchers. For this reason, Turkish versions of the research scales were used in this study. The questionnaires were sent to the participants via post, and of 500 questionnaires 326 (65\%) were returned. According to Babbie (2001) a response rate of $65 \%$ is good. 33 out of 326 surveys returned were incomplete and inaccurate and so not put into the analysis, and the remaining 293 were added to the analysis. Considering that the related aviation company has a total of 500 full-time employees, it can be statistically said that the sample can represent the study population (https:// www.surveysystem.com). The majority of participants were men (68 percent), 45 percent were between the ages of 26-35 years, 64 percent reported educational levels as bachelor's degrees, and their average job tenure was 5.56 years.

\subsection{Measures}

Employee advocacy scale. The employee advocacy scale includes a seven-item scale improved by Yeh (2014). The Turkish adaptation of scale was done by Akgunduz and Sanlı (2016). Sample items included "my company attempts to improve employee satisfaction" and so on $(\mathrm{a}=0.95)$.

Perceived insider status. I used Stamper and Masterson's (2002) six-item measures of PIS. The Turkish adaptation of scale was done by Ozdevecioglu and Balci (2011). One of the items on the scale is "my work organization makes me believe that I am included in it" $(a=0.94)$.

Power distance. Power distance was tested with an adapted version of Dorfman and Howell's (1988) of the five-item organizational culture scale. The scale is adapted to Turkish by Akyol (2009). Sample items included "a supervisor use of authority and power is often necessary to assure that work is done efficiently" and so on ( $\alpha=0.73)$.

Psychological well-being. Lastly, for measuring participants'PWB levels, the PWB scale with eight-item developed by Diener et al. (2010) was used. The Turkish adaptation of scale was done by Telef (2013). One of the samples is "I lead a purposeful and meaningful life" 
$(a=0.91)$. For all measures seven-point Likert-type scale (1="strongly agree"; 7="strongly disagree") were used.

I used SPSS 22.0 program to test reliability and intercorrelations of scales and used AMOS for testing the validity of scales. For testing the research hypotheses, SPSS Macro developed by Preacher and Hayes (2004) was used.

\section{RESULTS}

\subsection{Confirmatory Factor Analysis}

Before testing the research hypothesis, the fit indexes of scales were tested using confirmatory factor analysis (CFA). I calculated six appropriate indices to determine the suitability of the model with the data. It is required to be examined the results of CFA and the model through fit indexes (Schreiber et al., 2006). There are many types of fit indexes used in researches. In this study, "degrees of freedom $\left(x^{2} / d f\right)$ ", "root mean square error of approximation (RMSEA),",comparative fit index $(\mathrm{CFI})$ ", "goodness of fit index (GFI)","non-normed fit index (NNFI)" and "standardized root mean residual (SRMR)" goodness fit indexes were used (Schreiber et al., 2006). The goodness fit indexes for each model found as a result of the analysis are given in Table 1.

Table 1: Fit Indexes of Scales

\begin{tabular}{lllllll}
\hline & X2/df & RMSEA & CFI & GFI & NNFI & SRMR \\
\hline EA & 2.468 & 0.065 & 0.989 & 0.967 & 0.982 & 0.027 \\
PIS & 2.335 & 0.061 & 0.991 & 0.975 & 0.985 & 0.026 \\
PD & 1.680 & 0.058 & 0.985 & 0.987 & 0.965 & 0.048 \\
PWB & 2.184 & 0.077 & 0.983 & 0.966 & 0.970 & 0.038 \\
\hline
\end{tabular}

(EA: employee advocacy; PIS: perceived insider status; PD: power distance; PWB: psychological well-being)

Another analysis that needs to be done before proceeding with the testing of the research hypotheses is to reveal whether there is a problem among the research variables in terms of discriminant validity as a whole. I checked discriminant validity by using two methods. First, the measurement model, which includes all variables (employee advocacy perceived insider status, power distance, and psychological well-being), has been tested with alternative models strategy (Anderson and Gerbing, 1988). As a result of the analyzes, it was found that the four-factor model had better good fit values than the alternative models $(\mathrm{X} 2(277)=558.244, \mathrm{p}=.02, \mathrm{RMSEA}=.06, \mathrm{CFI}=.96, \mathrm{GFI}$ $=.95, \mathrm{NNFI}=.96, \mathrm{SRMR}=.05)$, and the factors in the four-factor model had discriminant validity with other factors. Second, for discriminant validity, the average variance extracted (AVE) values must be greater than .50 (Fornell and Larcker, 1981). Results showed that the AVE value of the scales (employee advocacy $=.76$, perceived insider status $=.77$, power distance $=.58$ and psychological well-being $=.61$ ) was higher than 0.50 . Thus, it can be said that discriminant validity is provided.

\subsection{Hypotheses Testing}

The research hypotheses were tested in two interconnected steps. In the first step, a simple mediation model was established thus determining the mediating effect of PIS in the relationship between employee advocacy and PWB without including power distance $(\mathrm{H} 1$, $\mathrm{H} 2, \mathrm{H} 3$, and $\mathrm{H} 4$ ). In the next step, power distance was included in the first step as a moderating variable and its moderating effect $(\mathrm{H} 5)$ in the relationship between PIS and PWB, and moderated mediation effect on the impact of employee advocacy on PWB through PIS (H6) were tested.

Table 2 shows the means, standard deviations and intercorrelations of scales. When the correlation values in the table are examined; it is seen that employee advocacy is positively correlated with PIS ( $r=0.62$; $p<0.01)$, and PWB $(r=0.51 ; p<0.01)$ and negatively correlated with power distance $(r=-0.18 ; p<0.01)$. In addition, PIS is positively correlated with PWB $(r=0.65$; $p<0.01)$, but it is not correlated with power distance $(r=$ -0.09). Table 2 shows the reliability of data by Cronbach alpha (in parentheses). As seen in the table all variables have high reliability (employee advocacy $a=0.95$; perceived insider status $a=0.94$; power distance $a=0.73$; psychological well-being $a=0.91$ ).

Table 2: Means, Standart Deviations and Intercorrelations of Scales

\begin{tabular}{lllllll}
\hline & $\mathbf{1}$ & $\mathbf{2}$ & $\mathbf{3}$ & $\mathbf{4}$ & $\mathbf{M}$ & $\mathbf{S D}$ \\
\hline EA & $(.95)$ & & & & 3.35 & 1.007 \\
PIS & $.62^{* *}$ & $(.94)$ & & & 3.68 & 1.060 \\
PD & $-.18^{* *}$ & -.09 & $(.73)$ & & 3.44 & 1.018 \\
PWB & $.51^{* *}$ & $.65^{* *}$ & $-.16^{*}$ & $(.91)$ & 3.71 & .843 \\
\hline
\end{tabular}

$\left(N=293 ;{ }^{* *} \mathrm{p}<0.01 ;{ }^{*} \mathrm{p}<0.05 ; \mathrm{EA}=\right.$ employee advocacy; $\mathrm{PIS}=$ perceived insider status; $\mathrm{PD}=$ power distance; $\mathrm{PW} B=$ psychological well-being)

\subsection{Test of Mediation}

To test the mediating effect of PIS in the relationship between employee advocacy and PWB I used SPSS macro provided by Preacher and Hayes (2004). The results obtained from this model (Table 3 ) inform 
about $\mathrm{H} 1, \mathrm{H} 2, \mathrm{H} 3$, and $\mathrm{H} 4$ hypotheses. Before analyzing the results, some conditions need to be mentioned concerning the existence of the mediating variable. Baron and Kenny (1986) argued that a few criteria must be met to talk about the existence of the mediation. According to these conditions: (a) employee advocacy predicts the PWB; (b) employee advocacy predicts the PIS; (c) PIS predicts the PWB; (d) when the effect of PIS is controlled, the relationship between employee advocacy and PWB can be statistically meaningless (full mediation effect) or there can be a decrease in the power of the relationship (partial mediation effect). For the statistical significance of the mediating effect, Sobel (1982) test need to be done. Sobel test suggests that indirect effect normally distributed (Preacher et al., 2007; Baron and Kenny, 1986; Fairchild and MacKinnon, 2009). This assumption is known as the abnormal distribution even if the indirect effect is normally distributed (Edwards and Lambert, 2007). For this reason, it is recommended to use the bootstrapping method to solve this problem (Preacher and Hayes, 2007; Edwards and Lambert, 2007). Bootstrapping is a nonparametric approach for effect-size estimation and hypothesis testing, making no assumptions about the existence of variables or distribution of samples (Preacher et al., 2007). It is possible to prevent power problems of indirect effect, brought with asymmetric and other abnormal sample distributions, through bootstrapped confidence intervals (Fairchild and MacKinnon, 2009).

In the context of these explanations, the presence of mediating effect can be mentioned in case of meeting the conditions revealed by Baron and Kenny (1986) (H1, $H 2, H 3$, and $H 4)$, and being significant of $z$ value $(p<$ $.01)$ obtained as a result of Sobel test. For this purpose, a model, not including the moderating variable (power distance), was established to test whether there is an indirect effect of employee advocacy on PWB through
PIS. The values for this model $(B, \mathrm{SE}, t$, and $p)$ were summarized in Table 3.

Table 3 presents the results for Hypotheses 1-4. Employee advocacy was positively associated with PWB, as demonstrated by a significant unstandardized regression coefficient $(B=0.14 ; t=8.34 ; p<0.05)$, and therefore the Hypothesis 1 was supported. The results related to Hypothesis 2 indicate that employee advocacy had a positive effect on PIS ( $B=0.65 ; t=11.29 ; p$ $<0.01)$. According to these results, it can be said that $\mathrm{Hy}$ pothesis 2 was supported. Furthermore, the results for the relationship between PIS and PWB were analyzed. The results showed that PIS affected PWB positively ( $B$ $=0.43 ; t=8.02 ; p<0.01)$, and based on this effect it can be said that Hypothesis 3 was supported. Finally, the Hypothesis 4 was tested to determine the mediating effect of PIS. It was found that there was an indirect effect transmitted by PIS in the relationship between employee advocacy and PWB $(B=0.28 ; \mathrm{p}<0.05)$. This result can also be stated as PIS has a partial mediation effect on the relationship between employee advocacy and PWB. The significance of the indirect effect can be determined by looking at the significance of the " $z$ " value resulting from the Sobel test (Sobel, 1982; Baron and Kenny, 1986). As a result of the Sobel test, the mediating effect was found to be significant (Sobel $z=6.52 ; p<0.01)$. Since the confidence interval for the Bootstrapped estimated value of the indirect effect does not include zero at 99\% significance level ( $\mathrm{LLCl}=$ 0.16 and $\mathrm{ULCl}=0.43$ ), we can say that Sobel test results are supported by Bootstrap results (Hayes and Preacher, 2014). According to this information, it can be said that PIS has a partial mediation effect on the relationship between employee advocacy and PWB. This result means that Hypothesis 4 is supported. Moreover, this result supports the existence of the mediating effect in terms of providing the conditions (supporting of the hypotheses $\mathrm{H1}, \mathrm{H} 2, \mathrm{H} 3$, and $\mathrm{H} 4$ ) set forth by Baron and Keeny (1986).

Table 3: Regression Analysis Results of the Mediating Effect

\begin{tabular}{lcccccc}
\hline & & & $\boldsymbol{B}$ & $\boldsymbol{S E}$ & $\boldsymbol{t}$ & $\boldsymbol{p}$ \\
\hline The direct effect of EA on PWB & & & 0.14 & 0.06 & 8.34 & 0.012 \\
EA has a positive effect on PIS & & & 0.65 & 0.06 & 11.29 & 0.000 \\
PIS has a positive effect on PWB & & & 0.43 & 0.05 & 8.02 & 0.000 \\
\hline & Value & SE & LL 95\% Cl & UL 95\% Cl & $\boldsymbol{z}$ & $\boldsymbol{p}$ \\
\hline Indirect effect and Sobel test & 0.28 & 0.043 & 0.19 & 0.39 & 6.52 & 0.000 \\
\hline & $\mathbf{M}$ & SE & LL 99\% Cl & UL 99\% Cl & & \\
\hline Bootstrapped indirect effect & 0.27 & 0.050 & 0.16 & 0.43 & &
\end{tabular}

$(N=293$; Bootstrap sample size $=5.000 . \mathrm{Cl}=$ Confidence Interval; $\mathrm{LL}=$ Lower Limit; UL= Upper Limit. EA=Employee Advocacy; PWB=Psychological Well-Being; PIS=Perceived Insider Status) 


\subsection{Test of Moderated Mediation}

The researchers (Edwards and Lambert, 2007; Preacher et al., 2007) found that 4 conditions must be fulfilled to be able to talk about moderated mediation (alternatively known as conditional indirect effect). When these conditions are adapted to the research scales; (a) PIS must affect PWB significantly; (b) the interaction between PIS and power distance must be significant when predicting PWB; (c) employee advocacy must has a significant effect on PWB; (d) employee advocacy must has a different conditional indirect effects on PWB at low and high power distance levels through PIS. Namely, the indirect effect of employee advocacy on PWB through PIS must be weak at low power distance, and strong at high power distance. It had been previously confirmed that the first and third conditions were supported $(\mathrm{H} 1$ and $\mathrm{H} 3)$.

Testing of Hypothesis 5 and Hypothesis 6, SPSS macro program was used (Hayes, 2013; model 14). This program demonstrates the variation of the conditional indirect effect relative to the different levels of the moderating variable, facilitating the implementation of the bootstrapping method, and provides explanatory and statistical information for the rejection or acceptance of hypotheses. As a result of the analysis, data for moderating effect $(\mathrm{H} 5)$ and conditional indirect effect (H6) were summarized in Table 4.

Table 4 presents the results for Hypotheses 5 and 6. In regards to Hypotheses 5, it was predicted that the positive relationship between PIS and PWB would be weaker for high power distance than for low power distance. As a result of the analysis, it was found that the effect of PIS and power distance interaction (PISXPD) on PWB was significant $(B=-0.12 ; t=-2.01 ; p<0.05)$. To say that Hypothesis 5 is fully supported, it must be revealed that the positive relationship between PIS and PWB is strong in the case of low power distance and vice versa. Figure 2 was formed using the data obtained to determine whether the effect of PIS on PWB shows significant differences according to the different levels of power distance.

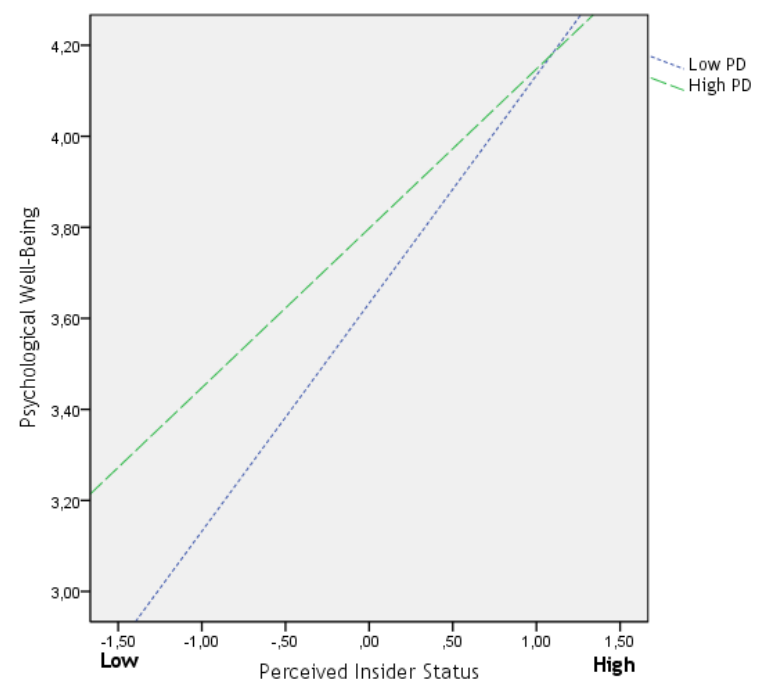

Figure 2: Power distance moderating the relationship between perceived insider status and psychological well-being.

Table 4: Regression Results for Moderated Mediation

\begin{tabular}{|c|c|c|c|c|}
\hline Predictor & $B$ & SE & $\mathbf{t}$ & $p$ \\
\hline \multicolumn{5}{|c|}{ DV $=$ Perceived Insider Status } \\
\hline Employee Advocacy & 0.65 & 0.06 & 11.21 & 0.00 \\
\hline \multicolumn{5}{|c|}{ DV=Psychological Well-Being } \\
\hline Perceived Insider Status (PIS) & 0.69 & 0.06 & 4.98 & 0.00 \\
\hline Power distance (PD) & 0.52 & 0.23 & 2.27 & 0.02 \\
\hline PISxPD & -0.12 & 0.06 & -2.01 & 0.04 \\
\hline Power Distance & Boot indirect effect & Boot SE & Boot z & Boot p \\
\hline \multicolumn{5}{|c|}{ The conditional indirect effect at Power Distance $=M \pm 1 S D$} \\
\hline$-1 S D(-0.78)$ & 0.33 & 0.06 & 5.5 & .000 \\
\hline$M(0.00)$ & 0.27 & 0.05 & 5.4 & .000 \\
\hline$+1 S D(0.78)$ & 0.21 & 0.05 & 4.2 & .000 \\
\hline
\end{tabular}

$\mathrm{DV}=$ Dependent variable 
As a result of the investigations, it was found that the relationship between PIS and PWB was weaker ( $B$ $=.35, \mathrm{t}=4.97, p<.01)$ for high power distance than for low power distance $(B=.50, t=7.77, p<.01)$. Therefore, Hypothesis 5 was supported. It was also seen that one of the moderated mediation conditions was met, which is the interaction between PIS and power distance must be significant when predicting PWB $(B=-0.12, t=2.01$, 95\%).

The strength of the hypothesized indirect effect is conditional on the value of the moderator (power distance; see Hypothesis 6). The results of Hypothesis 6 were examined by taking into consideration the conditional indirect effect recommendations. The conditional indirect effect refers to the significant change of indirect effect according to the specific levels of the moderating variable (Preacher et al. 2007). The indirect and positive effect of employee advocacy on PWB through PIS has significantly changed according to the different levels of power distance. In conclusion, the condational indirect effect of employee advocacy on PWB through PIS was examined at two values of power distance: one standard deviation above the mean (0.78), one standard deviation below the mean $(-0.78)$. Besides, when the results of the model index are examined, it can be said that the moderated mediation index is significant due to not containing 0 (zero) ( $B$ $=-0.11,95 \% \mathrm{Cl}-.13$, to -.03$)$. Thus, Hypothesis 6 was supported, such that the indirect and positive effect of employee advocacy on PWB (through PIS) was weak when power distance is high but not when it is low.

\section{DISCUSSION}

The results of this study are based on the data obtained from the survey conducted on the full-time employees of a company operating in the aviation industry. The aviation industry is a sensitive service industry as it is affected very quickly by many internal (employees' attitudes, the organization's attitudes towards customers, etc.) and external (economic crises, meteorological events, etc.) factors (Yeh, 2014). In this study, the effects of employees' perceived advocacy and insider status levels on their PWBs that shape employees'attitudes and behaviors towards customers were investigated according to the low and high levels of power distance. If employees' efforts to improve their quality of life and PWBs are not supported by company policies (lack of employee advocacy), all efforts of employees will be wasted (Henning, 2015). In the absence of sufficient resources and decision-making powers, it is difficult for employees to make the expected effort. It is known that such situations negatively influence employees' PWBs (Tourigny et al., 2010). The studies (Karasek, 1979; Tourigny et al., 2010) showed that employees experienced a lot of work stress in industries with time pressure and excessive workload. Similarly, as a result of researches, it was determined that the PWB levels of those who experienced work-induced stress decreased according to the amount of stress they experienced (Anand and Nagle, 2016).

\subsection{Theoretical Implications}

I believe the results of this study contribute to the literature by corroborating and extending previous research in several ways. Past researchers have not paid enough attention to the relationship between employee advocacy and psychological well-being. This study contributes to the literature in terms of being the first study, and to my knowledge, which deals with the relationship between these two variables with the conditional indirect effect model. In other words, this study provides a complex model that broadens the focus of employee advocacy research and how employee advocacy affects psychological well-being.

I proposed and tested a moderated mediation model that shows PIS the mediators and power distance as the moderator in relationships between employee advocacy and PWB. Research findings are demonstrated that the relationship between employee advocacy and PWB is more complex than was prior researchers' findings. Studies related to PWB usually ruled out culture (Ryff and Keyes, 1995; Panaccio and Vandenberghe, 2009). Only limited studies had paired with culture and PWB together (Rasulzada, 2007; Leersnyde et al., 2015). Also, limited studies examined PWB in the service sector (Zakaria et al., 2014). In the service sector employees' well-being have a very critical effect on organization performance (Wright and Cropanzano, 2000; Zakaria et al., 2014). This study suggests that increasing the PWB level is not only depending on employee advocacy and employees PIS level; it also depends on organizational culture.

The present study results also contribute to literature a better understanding of social exchange theory. Social exchange theory conceptualized power in terms of resources and the exchange of resources. Power differentiation affects social structures due to power asymmetry in relationships. It is possible to state that the benefit and harm owned by the social exchange are also affected by this power differentiation 
and asymmetry. The frequency and distribution of the social exchange, in which the balance and symmetry of power is decisive, is an indicator of the satisfaction that the individual perceives from this exchange (Zafirovski, 2005). The balance of power and symmetry of power mean more satisfaction. The fact of satisfaction in social exchange may also mean that this relationship will continue. According to Emerson (1962), the social exchange relationship of employees with a high perception of power distance is weaker than those with a low perception of power distance. As the basis of social exchange is mutual interdependence, power distance is an important factor in these relations. It can be said that these study results support Emerson's (1962) assumptions about the relationship between social exchange and power. In other words, in terms of social exchange theory, organizations desire that employees have a high level of psychological well-being, while employees want the organization's policies to be transparent and their contribution to the organization to be valued by the organization. The strengthening of this social exchange relationship takes place when the organization has a culture where low power distance is applied.

\subsection{Practical Implications}

For managers and organizations, this study suggests some practical implications. First, the results of the research demonstrate that the ground service workers' psychological well-being and perceived internality status are directly affected by the employee advocacy (Hypotheses 1 ve Hipotez 2 are supported). When the employee advocacy increases, the psychological well-being and perceived insider status of the employees also increase (Eisenberger et al., 1986). Employee advocacy refers to the transparency of the company's employee policy and the willingness to act for the interests of the employees. Employee advocacy also depends on how employees perceive managerial practices (Yeh, 2014). Managers can increase employee advocacy by taking into account employees' complaints, protecting them from discriminatory employment practices, treating them fairly and making them feel that their contribution to the organization is important (Şanlı, 2016). Second, research findings revealed that perceived insider status mediated the relationship between employee advocacy and psychological well-being (Hypothesis 3 is supported). In the increase of employee's PWB, it is necessary not only the employee advocacy is high, but also employee's PIS must be high. In addition, the happiness of employees has a considerable effect on organizational goals for all sectors especially the service sector (Eisenberger et al., 2001; Stamper and Masterson, 2002). Managers can positively contribute to the psychological well-being of employees by increasing their insider status and employee advocacy perception thanks to the practices that employees feel valued and part of the organization (eg, feedback, promotion, and included in decisions). Third, hypothesis 5 predicted that increasing employees' PWB levels can be provided by increasing employees' PISs and level of power distance. Research findings demonstrate that the positive effect of perceived insider status on psychological well-being is strong when power distance is low, and weak power distance is high (Hypothesis is 5 supported). This study also highlighted the positive indirect effect of employee advocacy on psychological well-being through perceived insider status is strong when power distance is low, and weak power distance is high (Hypothesis is 6 supported). In organizations with a high power distance, the positive effects of employee advocacy and perceived insider status on psychological well-being are reduced. Because in such organizations, the delegation of authority is problematic, the transparency of the organization's management policies and the willingness to act for the interests of employees (employee advocacy) are reduced (Giapponi and Scheraga, 2007). In addition, the high power distance causes the employees' perceived organizational support and justice perceptions to be weakened, thereby decreasing the perceived insider status and not seeing themselves as part of the organization (Zheng et al., 2019). For this reason, to increase the psychological well-being of the employees, organizational managers must create an organizational culture with a low power distance.

\subsection{Limitations and Future Research}

In this part, the limitations and recommendations for future studies were mentioned. The first limitation of the study relates to the use of cross-sectional self-reported data. Because of the use of a cross-sectional method, this study does not provide information about the causality aspect of the study. Podsakoff et al. (2003) revealed that self-reported data may cause common method bias. The common method bias may cause the correlation values between scales to be greater than normal. However, Podsakoff et al. (2012) claimed that it would be wrong to say that the interactions between scales are definitely due to common method variance. Although the reliability and validity of the research scales have been proven in many studies before and 
the differences of scales have been demonstrated by confirmatory factor analysis in this study, it cannot be said that there is no common method variance. Future studies can solve common method bias problem by collecting data from different sources at different times. The use of power distance from the cultural dimensions introduced by Hofstede $(1980,2001)$ as a moderating variable might be perceived as the third limitation of this study. In many studies, power distance was used as a moderating variable (Zhang and Begley, 2010; Purwanto, 2018; Thomas, 2015; Gul et al., 2018). Future studies can also include different cultural dimensions (masculinity-femininity, individualism-collectivism, etc.) in the model, resulting in more comprehensive results in terms of cultural impact (Gul et al., 2018). Lastly, the collection of research data only in Turkey can be considered as another constraint. Hofstede (1980) revealed that power distance is a cultural indicator that differs from society to society or country to country. He determined that power distance is low in some countries (e.g., America, Germany, England) while high in some countries (e.g., Mexico, India, Brazil, etc.). Turkey is among the countries with high power distance. As power distance varies from country to country, different results may be obtained in countries with low power distances. 


\section{REFERENCES}

Akgunduz, Y. and Sanli, S. C. (2017). The effect of employee advocacy and perceived organizational support on job embeddedness and turnover intention in hotels, Journal of Hospitality and Tourism Management, 31, pp. 118-125.

Akyol, Ş. (2009). Örgüt Kültüründe Güç Mesafesi ve Liderlik İlişkisi [Power Dıstance and Leadership Relatıon in Organızatıonal Culture]. (Unpublished Doctoral Thesis). Marmara University Social Science Institute: İstanbul.

Anand, K. and Nagle, Y. K. (2016). Perceived stress as predictor of psychological well-being in Indian youth, The International Journal of Indian Psychology, 3(4), pp. 211-217.

Anderson, J. C. and Gerbing, D. W. (1988). Structural equation modeling in practice: $A$ review and recommended two-step approach. Psychological Bulletin, 103, pp. 411-423.

Aykan, E. and Akgül, H. (2018). Çalışanların örgütsel destek ve işgören avukatlığı algılarının işten ayrılma niyetleri üzerindeki etkisi: Kayseri lojistik sektöründe bir uygulama [The effect of organizational support and employee advocacy perceptions of employees' on their turnover intention: an application in Kayseri logistics industry]. Düzce Üniversitesi Sosyal Bilimler Enstitüsü Dergisi, 8(1), pp. 34-50.

Babbie, E. (2001). The Practice of Social Research. 9th Edition, Wadsworth Thomson, Belmont.

Baron, R. M. and Kenny, D. A. (1986). The moderatormediator variable distinction in social psychological research: Conceptual, strategic, and statistical considerations, Journal of Personality and Social Psychology, 51, pp. 1173-1182.

Bergiel, E. B., Bergiel, B. J., and Upson, J. W. (2012). Revisiting Hofstede's dimensions: examining the cultural convergence of the United States and Japan, American Journal of Management, 12(1), pp. 69-79.

Ban, H. J. and Kim, H. S. (2019). Understanding customer experience and satisfaction through airline passengers' online review. Sustainability, 11(15), pp. 1-17.

Blau, P. (1964). Power and Exchange in Social Life. New York: J Wiley and Sons.

Bradburn, N. M. (1969). The Structure of Psychological Well-Being. National opinion research center, Chicago: Aldine Publishing Company.

Buonocore, F., Metallo, C., and Salvatore, D. (2009). Behavioural consequences of job insecurity and perceived insider status for contingent workers, In System Congress, http://www.woa2009.it/papers/ Buonocore_Metallo_Salvatore.pdf, 1-29, (Accessed date 09.14.2018), pp. 1-29.

Caesens, G., Stinglhamber, F., and Ohana, M. (2016). Perceived organizational support and well-being: A weekly study. Journal of Managerial Psychology. 31(7), pp. 1214-1230.

Chan, K. W. and Wan, E. W. (2012). How can stressed employees deliver better customer service? The underlying self-regulation depletion mechanism, Journal of Marketing, 76, pp. 119-137.

Cropanzano, R. and Mitchell, M. S. (2005). Social exchange theory: An interdisciplinary review, Journal of Management, 31(6), pp. 874-900.

Dai, L. and Chen, Y. (2015). A systematic review of perceived insider status, Journal of Human Resource and Sustainability Studies, 3, pp. 66-72.

Dalgıc, A., Birdir, K., and Guler, O. (2016). The effect of employee advocacy on role conflict and role ambiguity pf workers: a research on hotel employees, 3rd International Congress of Tourism and Management Researches. Antalya, Turkey, pp. 1193-1212.

Daniels, K. and Harris, C. (2000). Work, psychological well-being and performance, Occupational Medicine, 50(5), pp. 304-309.

Daniels, M. A. and Greguras, G. J. (2014). Exploring the nature of power distance: Implications for micro-and macro-level theories, processes, and outcomes, Journal of Management, 40(5), pp. 1202-1229.

Diener, E., Kahneman, D., and Helliwell, J. (2010). International Differences in Well-Being, New York: Oxford University Press.

Dorfman, P. W. and Howell, J. P. (1988). Dimensions of national culture and effective leadership patterns: Hofstede revisited, In E. G. McGoun (Ed.), Advances in International Comparative Management, 3, pp. 127-150.

Edwards, J. R. and Lambert, L. S. (2007). Methods for integrating moderation and mediation: a general analytical framework using moderated path analysis, Psychological Methods, 12(1), pp. 1-22.

Emerson, R. M. (1962). Power-dependence relations, American Sociological Review, pp. 31-41.

Emerson, R. M. (1976). Social exchange theory, Annual Review of Sociology, 2, pp. 335-362. 
Eisenberger, R., Huntington, R., Hutchison, S., and Sowa, D., (1986). Perceived organizational support. J. Appl. Psychol. 71 (3), pp. 500e507.

Fairchild, A. J. and MacKinnon, D. P. (2009). A general model for testing mediation and moderation effects, Prevention Science, 10, pp. 87-99.

Fornell, C., and Larcker, D. F. (1981). Evaluating structural equation model with unobservable variables and measurement error. Journal of Marketing Research, 18(1), pp. 39-50.

Giapponi, C. and Scheraga, C. (2007). The Impact of Cross-Cultural Factors on Corporate Governance Transparency: The Implication for Strategic Alliances in the Airline Industry (No. 1428-2016-118587).

Gul, H., Usman, M., Liu, Y., Rehman, Z., and Jebran, K. (2018). Does the effect of power distance moderate the relation between person environment fit and job satisfaction leading to job performance? Evidence from Afghanistan and Pakistan, Future Business Journal, 4, pp. 68-83.

Hayes, A. F. (2013). Introduction to Mediation, Moderation, and Conditional Process Analysis: A Regression-Based Approach. New York: The Guilford Press.

Hayes, A. F. and Preacher, K. J. (2014). Statistical mediation analysis with a multicategorical independent variable, British Journal of Mathematical and Statistical Psychology, 67, pp. 451-470.

Helmreich, R. L., Wilhelm, J. A., Klinect, J. R., and Merritt, A. C. (2001). Culture, error and crew resource management. Improving teamwork in organizations: Applications of Resource Management Training, 305331.

Hofstede, G. (1980). Culture and organizations, International Studies of Management and Organization, 10, pp. 15-41.

Hofstede, G. (1984). Culture's consequences: International Differences in Work-Related Values, London: Sage Publigations.

Horng, J. S., Tsai, C. Y., Hu, D. C., and Liu, C. H. (2016). The role of perceived insider status in employee creativity: Developing and testing a mediation and three-way interaction model. Asia Pacific Journal of Tourism Research, 21(sup1), pp. 53-75.

Kenny, D. A., Kashy, D. A., and Bolger, N. (1998). Data analysis in social psychology, In D. T. Gilbert, S. T. Fiske, and G. Lindzey (Eds.), The handbook of social psychology. Boston, MA: McGraw-Hill, pp. 233-265.

Kim, J. (2008). Perception of social exchange and psychological well-being: a study focusing on social exchange in Korea between 1997 and 2000, Journal of Applied Social Psychology, 38(11), pp. 2821-2858.
Kim, D.-O. (2009). Employees' perspective on non-union representation: A com-parison with unions, Economic and Industrial Democracy, 30(1), pp. 120-151.

Liao, S. H., Widowati, R., Hu, D. C., and Tasman, L. (2017). The mediating effect of psychological contract in the relationships between paternalistic leadership and turnover intention for foreign workers in Taiwan, Asia Pacific Management Review, 22(2), pp. 80-87.

Lindbeck, A. and Snower, D. J. (2001). Insiders versus outsiders, Journal of Economic Perspectives, 15, pp. 165-188.

March, J. G. and Simon, H. A. (1958). Organizations, New York: Wiley.

$\mathrm{Ni}, \mathrm{C}$. and Wang, Y. (2015). The impact of perceived organizational support and core self-evaluation on employee's psychological well-being. Journal of Human Resource and Sustainability Studies, 3(02), pp. 73-81.

Panaccio, A. and Vandenberghe, C. (2009). Perceived organizational support, organizational commitment and psychological well-being: A longitudinal study, Journal of Vocational Behavior, 75, pp. 224-236.

Podsakoff, P. M., MacKenzie, S. B., and Podsakoff, N. P. (2012). Sources of method bias in social science research and recommendations on how to control it, Annual Review of Psychology, 63, pp. 539-569.

Podsakoff, P. M., MacKenzie, S. B., Lee, J. Y., and Podsakoff, N. P. (2003). Common method biases in behavioral research: A critical review of the literature and recommended remedies, Journal of Applied Psychology, 88(5), pp. 879-903.

Preacher, K. J., Rucker, D. D., and Hayes, A. F. (2007). Addressing moderated mediation hypotheses: Theory, methods, and prescriptions, Multivariate Behavioral Research, 42(1), pp. 185-227.

Purwanto, E. (2018). Moderation effects of power distance on the relationship between job characteristics, leadership empowerment, employee participation and job satisfaction: A conceptual framework, Academy of Strategic Management Journal, 1(1), pp. 1-9.

Rasulzada, F. (2007). Organizational creativity and psychological well-being. Lund University Department of Psychology (Published Doctoral Thesis), http:// www. farida. se/Farida_Rasulzada_book. pdf, 18, 2014.

Raub, S. P. (2016). Perceived insider status and job design predict job attitudes and work performance of restaurant employees, Journal of Hospitality and Tourism Research, 20(10), pp. 1-24. 
Ryff, C. D. (1989). Happiness is everything, or is it? Explorations on the meaning of psychological well-being, Journal of Personality and Social Psychology, 57(6), pp. 1069-1081.

Ryff, C. D. (1995). Psychological well-being in adult life, Current Directions in Psychological Science, 4(4), pp. 99-104.

Ryff, C. D. and Keyes, C. L. M. (1995). The structure of psychological well-being revisited", Journal of Personality and Social Psychology, 69(4), pp. 719-727.

Schreiber, J. B., Nora, A., Stage, F. K., Barlow, E. A., and King, J. (2006). Reporting structural equation modeling and confirmatory factor analysis results: A review, The Journal of Educational Research, 99(6), pp. 323-338.

Sobel, M. E. (1982). Asymptotic confidence intervals for indirect effects in structural equation models, Sociological Methodology, 13, pp, 290-312.

Stamper, C. L. and Masterson, S. S. (2002). Insider or outsider? How employee perceptions of insider status affect their work behavior, Journal of Organizational Behavior: The International Journal of Industrial, Occupational and Organizational Psychology and Behavior, 23, pp. 875-894.

Steel, P., Taras, V., Uggerslev, K., and Bosco, F. (2018). The happy culture: A theoretical, meta-Analytic, and empirical review of the relationship between culture and wealth and subjective well-being, Personality and Social Psychology Review, Vol. 22, pp. 128-169.

Şanlı, S. C. (2016). İşgören avukatlığı ve algılanan örgütsel desteğin çalışanların işe gömülmüşlük ve işten ayrılma niyeti üzerine etkisi: Otel çalışanları üzerine bir araştırma [The effects of employee advocacy and perceived organizational support on job embeddedness and intentions to quit job: A study on hotel employees] (Yayınlanmamış Yüksek Lisans Tezi). Mersin Üniversitesi Sosyal Bilimler Enstitüsü Turizm İşletmeciliği Anabilim Dalı, Mersin.

Telef, B. B. (2013). Psikolojik iyi oluş ölçeği: Türkçeye uyarlama, geçerlik ve güvenirlik çalışması [The adaptation of psychological well-being into Turkish: $A$ validity and reliability study]. Hacettepe Üniversitesi Eğitim Fakültesi Dergisi, 28(28-3), pp. 374-384.

Thomas, D. (2015). The moderating effects of power distance and collectivism on empowering leadership and psychological empowerment and self-leadership in international development organizations, Faculty Publications - School of Business. 80.
Türeli, N. Ş., Durmaz, V., Bahçecik, Y. S., and Akay, S. S. (2019). An analysis of importance of innovatice behaviors of ground handling human resources in ensuring customer satisfaction. Procedia Computer Science, 158, pp. 1077-1087.

Volmer, J., Niessen, C., Spurk, D., Linz, A., and Abele, A. E. (2011). Reciprocal relationships between leader-member exchange (LMX) and job satisfaction: A cross-lagged analysis, Applied Psychology, 60(4), pp. 522-545.

Wright, T. A. and Cropanzano, R. (2000). Psychological well-being and job satisfaction as predictors of job performance, Journal of Occupational Health Psychology, 5(1), pp. 84-94.

Wright, T. A. and Cropanzano, R. (2004). The role of psychological well-being in job performance: A fresh look at an age-old quest, Organizational Dynamics, 33(4), pp. 338-351.

Yayla-Kullu, H. M., Tansitpong, P., Gnanlet, A., McDermott, C. M., and Durgee, J. F. (2015). Impact of national culture on airline operations, Operations Management Research, 8(3-4), pp. 101-117.

Yeh, Y. P. (2014). Exploring the impacts of employee advocacy on job satisfaction and organizational commitment: Case of Taiwanese airlines, Journal of Air Transport Management, 36, pp. 94-100.

Zafirovski, M. (2005). Social Exchange Theory under Scrutiny: A Positive Critique of its EconomicBehaviorist Formulations. Electronic Journal of Sociology, 2(2), pp. 1-40.

Zakaria, M., Abdulatiff, N. K., and Ali, N. (2014). The role of wellbeing on performance in services sector, Procedia-Social and Behavioral Sciences, 164, pp. 358-365.

Zhang, Y. and Begley, T. M. (2011). Power distance and its moderating impact on empowerment and team participation, The International Journal of Human Resource Management, 22(17), pp. 3601-3617.

Zheng, X., Zhu, W., Zhao, H., and Zhang, C. (2015). Employee well-being in organizations: Theoretical model, scale development, and cross-cultural validation, Journal of Organizational Behavior, 36, pp. 621-644.

Zheng, X., Li, L., Zhang, F., and Zhu, M. (2019). The roles of power distance orientation and perceived insider status in the subordinates' Moqi with supervisors and sustainable knowledge-sharing. Sustainability, 11(5), pp. 1-17. 